University of Nebraska - Lincoln

DigitalCommons@University of Nebraska - Lincoln

Agronomy \& Horticulture -- Faculty Publications

Agronomy and Horticulture Department

4-9-2007

\title{
Distribution of the arbuscular mycorrhizal biomarker C16:1 cis 11 among neutral, glyco and phospholipids extracted from soil during the reproductive growth of corn
}

\author{
Maria S. Grigera \\ University of Nebraska-Lincoln \\ Rhae A. Drijber \\ University of Nebraska-Lincoln, rdrijber1@unl.edu \\ Rebecca A. Shores-Morrow \\ University of Nebraska-Lincoln \\ Brian J. Wienhold \\ University of Nebraska-Lincoln, Brian.Wienhold@ars.usda.gov
}

Follow this and additional works at: https://digitalcommons.unl.edu/agronomyfacpub

Part of the Plant Sciences Commons

Grigera, Maria S.; Drijber, Rhae A.; Shores-Morrow, Rebecca A.; and Wienhold, Brian J., "Distribution of the arbuscular mycorrhizal biomarker C16:1 cis11 among neutral, glyco and phospholipids extracted from soil during the reproductive growth of corn" (2007). Agronomy \& Horticulture -- Faculty Publications. 32.

https://digitalcommons.unl.edu/agronomyfacpub/32

This Article is brought to you for free and open access by the Agronomy and Horticulture Department at DigitalCommons@University of Nebraska - Lincoln. It has been accepted for inclusion in Agronomy \& Horticulture -Faculty Publications by an authorized administrator of DigitalCommons@University of Nebraska - Lincoln. 


\title{
Distribution of the arbuscular mycorrhizal biomarker C16:1cis11 among neutral, glyco and phospholipids extracted from soil during the reproductive growth of corn ${ }^{2}$
}

\author{
Maria S. Grigera $^{a}$, Rhae A. Drijber ${ }^{\mathrm{a}, *}$, Rebecca H. Shores-Morrow ${ }^{\mathrm{a}}$, Brian J. Wienhold ${ }^{\mathrm{b}}$ \\ ${ }^{a}$ Department of Agronomy and Horticulture, University of Nebraska-Lincoln, 279 Keim Hall, Lincoln, NE 68583-0915, USA \\ b ARS-USDA, 120 Keim Hall, Lincoln, NE 68583-0934, USA
}

Received 28 July 2006; received in revised form 22 December 2006; accepted 11 January 2007

Available online 15 February 2007

\begin{abstract}
Arbuscular mycorrhiza (AM) fungi form symbiotic relationships with the majority of land plants and are known for their positive effects on plant $\mathrm{P}$ acquisition and soil quality. The extramatrical growth of the mycelium is a key factor in nutrient acquisition by the symbiont. Soil grinding and extraction/fractionation of lipids were used in a field experiment to identify probable sources of the AM biomarker C16:1 cis11 and its functional significance during reproductive growth of corn (Zea mays L.). Chambers, enclosed with a 1 mm mesh fabric to allow roots and hyphae to pass into the enclosed soil volume, were installed in two field sites cropped to continuous corn in central Nebraska. The chambers were installed at tasselling and removed after 3,6 and 9 weeks. Soil from the chambers was analyzed by ester-linked fatty acid (EL-FAME) and chloroform-methanol fatty acid (CM-FAME) analysis. We also separated and analyzed the neutral lipid (NLFA), glycolipid (GLFA) and phospholipid (PLFA) fatty acid fractions. Roller milling the soil gave up to two-fold increases in the recovery of EL- and CM-FAMEs common to saprophytic fungi (C16:0, C18:1cis9, C18:2cis9,12) and AM fungi (C16:0, C16:1cis11, C18:1cis11) but not those specific to bacteria or fauna. Resistant AM fungal structures were enriched in NLFA and GLFA C16:1 cis11, but not PLFA, indicating that storage lipids and possibly cell-wall lipids are released by roller milling. Similar proportional increases in C16:1cis11 on roller milling indicates that mild alkaline hydrolysis (EL-FAME) is as inefficient as chloroform-methanol (CM-FAME) in extracting lipids from AM spores. EL- and CM-FAME C16:1 cis11 increased by one-third between R5 and R6, indicating $\mathrm{C}$ allocation from the plant to the $\mathrm{AM}$ fungus during the reproductive stages of corn. This increase was attributed to accumulation of NLFA and GLFA in lipid-containing structures of the extramatrical mycelium and AM structures within roots, not increased sporulation. We propose EL-FAME C16:1 cis 11 as a simple measure of AM biomass in soils that largely reflects the AM hyphal network important to nutrient acquisition by the plant.
\end{abstract}

(C) 2007 Elsevier Ltd. All rights reserved.

Keywords: Mycorrhiza; AM fungi; C16:1cis11; FAME; El-FAME; CM-FAME; NLFA; GLFA; PLFA; Corn

\section{Introduction}

Arbuscular mycorrhizal (AM) fungi form symbiotic relationships with most land plants and are recognized for their positive effects on plant growth and soil quality (Smith and Read, 1997). This relationship benefits both

\footnotetext{
The US Department of Agriculture Research Service, Northern Plains Area is an equal opportunity/affirmative action employer and all agency services are available without discrimination.

*Corresponding author. Tel.: + 1402472 0770; fax: + 14024727904 .

E-mail address: rdrijber1@unl.edu (R.A. Drijber).
}

plant and fungus. The plant acquires nutrients more efficiently than can be accomplished by the root system alone and the fungi are provided a $\mathrm{C}$ source. Extramatrical growth of the mycelium is a key factor in nutrient acquisition by the mycorrhizal symbiont (Olsson et al., 1997). In AM fungi, C is stored and transported as lipid bodies. Plant sugars in intraradical fungal structures are converted into lipids that are translocated to the extraradical mycelium (Pfeffer et al., 1999) to be used for mycelial growth and sporulation.

Lipid fractions are useful for the study of AM fungal growth and morphogenesis. The proportion of neutral 
lipids in old AM hyphae was found to be higher in external mycelium than in internal mycelium (Olsson and Johansen, 2000). Triacylglycerol degradation during spore germination was demonstrated by Gaspar et al. (1994). After 10 days of germination, the triacylglycerols were reduced to nearly one-fourth of their initial concentration. Simultaneously, phospholipids tripled their concentration during the first 5 days of germination, and continued to increase for 2 weeks. During germination, triacylglycerols provide energy and $\mathrm{C}$ for the synthesis of phospholipids, which are structural molecules of membranes needed to form the germ tube (Gaspar et al., 1997). Thus, neutral and phospholipids dynamics are of interest when studying the temporal allocation of $\mathrm{C}$ from plant to fungus as related to fungal growth dynamics.

The fatty acid methyl ester (FAME) C16:1 cis 11 is often used as a biomarker for AM fungi in roots (Graham et al., 1995; Olsson and Johansen, 2000) and soils (Olsson, 1999). Graham et al. (1995) examined the FAME composition of spores of the order Glomales and found that C16:1cis 11 accounted for more than $50 \%$ of the total fatty acids in all isolates of Acaulospora and Eutrophospora and most isolates of Glomus and Scutellospora. The amount of C16:1cis11 per unit biomass in the mycelium varied greatly for neutral lipids, but not for phospholipids, making phospholipid fatty acid (PLFA) C16:1cis11 a better indicator of mycelial biomass (Olsson, 1999).

In soil systems, levels of PLFA are often too low and insensitive to detect changes in mycorrhizal fungal biomass (Olsson, 1999). Olsson's extensive research into the utility of PLFA and neutral lipid fatty acid (NLFA) C16:1 cis 11 has shown both to have reasonable correlations with hyphae and spores in soil-sand mixes, and to assess hyphae, arbuscules and vesicles in roots (Olsson et al., 1997; Olsson and Johansen, 2000; van Aarle and Olsson, 2003). However, only $0.2 \%$ of the spore and $0.4 \%$ of the hyphal biomass consisted of phospholipids. Given these concentrations, low-extraction efficiency may also affect the final estimation of fungal biomass by PLFAs (Olsson and Johansen, 2000). It is also important to note that these experiments were conducted under controlled conditions. In agricultural soils under field conditions, the extraction efficiency of phospholipids may be even smaller, making it even more difficult to detect changes over time.

The FAME biomarker C16:1 cis11 provides an index of $\mathrm{C}$ partitioning during the colonization process based on relative amounts of this fatty acid in different structures for fungal growth and lipid storage (Graham et al., 1995). We used this approach to study plant $\mathrm{C}$ allocation to AM fungi in soil samples collected during the reproductive growth stage of corn (Zea mays L.). Prior research demonstrated an increase in the AM biomarker C16:1 cis 11 in ester-linked fatty acids (EL-FAMEs) extracted from soil using $0.2 \mathrm{M}$ potassium hydroxide in methanol during reproductive growth of corn (Grigera et al., 2007). Soil grinding and extraction/fractionation of lipids were then used to identify probable sources of the AM biomarker C16:1cis11 and its functional significance during the reproductive growth of corn. We hypothesize that mild alkaline hydrolysis (i.e. ELFAMEs) is minimally effective at extracting spores, thus reflecting largely the 'physiologically active' portion of the fungus important to nutrient acquisition by corn.

\section{Materials and methods}

\subsection{Experimental site}

A field study was conducted during 2004 near Shelton, NE $\left(40^{\circ} 45^{\prime} 01^{\prime \prime} \mathrm{N}, 98^{\circ} 46^{\prime} 01^{\prime \prime} \mathrm{W}\right)$. Soils at the site are Hord silt loam (Fine-silty, mixed mesic Pachic Argiustoll, 0-1\% slope) and Blendon loam (Coarse-loamy, mixed mesic Pachic Haplustoll, 0-1\% slope). Continuous corn was grown from 1990 to 1996 under conventional disk tillage with furrow irrigation. Since 1996, reduced tillage with sprinkler irrigation was used. Prior to planting, $168 \mathrm{~kg} \mathrm{Nha}^{-1}$ as urea ammonium nitrate solution was incorporated with a field cultivator. Corn (Pioneer 33B51) was planted on 2 May 2004 with $20 \mathrm{kgPha}^{-1}$, and $13 \mathrm{~kg} \mathrm{Nha}^{-1}$ as diammonium phosphate applied adjacent to the seed. Stand density was 71,600 plants $^{-1}$ and field average yield was $12.2 \mathrm{Mgha}^{-1}$ at $155 \mathrm{~g} \mathrm{~kg}^{-1}$ moisture content.

\subsection{Preparation, installation and removal of chambers}

A bulk soil sample was collected from the 0 to $15 \mathrm{~cm}$ depth on 22 June, passed through a $6 \mathrm{~mm}$ mesh sieve to remove plant residues then stored moist at $4{ }^{\circ} \mathrm{C}$ until the chambers were prepared. The chambers were made of PVC with a wall thickness of $0.6 \mathrm{~cm}$, a diameter of $10 \mathrm{~cm}$ and a height of $4.5 \mathrm{~cm}$. The radial sides of the rings were enclosed with a $1 \mathrm{~mm}$ mesh fabric to allow penetration by both corn roots and hyphae (Sefar America Inc., Depew, NY). The ring was filled with approximately $425 \mathrm{~g}$ of soil and packed to a bulk density of $1.2 \mathrm{~g} \mathrm{~cm}^{-3}$. Soil in each ring was amended with $20 \mathrm{ml}$ of distilled water and thoroughly mixed. The prepared chambers were placed in a plastic bag and stored at $4{ }^{\circ} \mathrm{C}$ until they were placed in the field. Three chambers were installed $10 \mathrm{~cm}$ apart from the corn plant in the furrow on 15 July in two field sites at the VT stage of corn (Ritchie et al., 1997).

One chamber from each site was removed 3, 6 and 9 weeks after installation [4 August (R3 stage, milk), 23 August (R5 stage, dent) and 13 September (R6, physiological maturity)]. The chambers were transported in a cooler to the laboratory, and opened. The soil was passed through a $4 \mathrm{~mm}$ sieve to remove visible organic residues, thoroughly mixed, air dried and divided in two: one subsample was roller milled and the other was not. Briefly, 10 stainless steel rods inside square bottles $(7.0 \mathrm{~cm}$ tall, $4.0 \mathrm{~cm}$ sides $)$ containing $2.5 \mathrm{~g}$ of soil per bottle were rolled for $16 \mathrm{~h}$. Roller milling results in a sample with smaller particles $(99.2 \%<100$ mesh) than with a ball-milling device $(83 \%$ 
$<100$ mesh) and thus provides a more uniform sample (Arnold and Schepers, 2004).

\subsection{Quantification, identification and classification of FAMES}

\subsubsection{Ester-linked (EL) FAMEs analysis}

Briefly, samples were hydrolyzed using freshly prepared $0.2 \mathrm{M}$ potassium hydroxide in methanol and the resulting FAMEs were partitioned into hexane (Johnson et al., 2004). Following saponification to release EL-FAMEs, methyl nonadecanoate $\left(0.05 \mu \mathrm{g} \mu \mathrm{l}^{-1}\right)$ was added to the extract as an internal standard.

Released FAMEs were separated by gas chromatography, using helium as a carrier gas and an Ultra 2 HP $(50 \mathrm{~m}$, $0.2 \mathrm{~mm}$ ID, $0.33 \mu \mathrm{m}$ film thickness) capillary column. The gas chromatograph was run in split mode (44:1) with a $45 \mathrm{~s}$ purge time. Injector and flame ionization detectors were maintained at 280 and $300^{\circ} \mathrm{C}$, respectively, and oven temperature was ramped from 50 to $160^{\circ} \mathrm{C}$ at $40^{\circ} \mathrm{C} \mathrm{min}{ }^{-1}$ and held for $2 \mathrm{~min}$, then ramped at $3{ }^{\circ} \mathrm{C} \mathrm{min}^{-1}$ to $300^{\circ} \mathrm{C}$ and held for $30 \mathrm{~min}$. The fatty acids were identified by retention time and confirmed by mass spectrometry. Concentrations of FAMEs were calculated from peak areas and reported as $\mathrm{nmolg}^{-1}$ soil.

\subsubsection{Chloroform-methanol extraction (CM-FAME) and separation into lipid classes}

A modified one-phase extraction procedure of Bligh and Dyer (White et al., 1979) was used to extract lipids from the soil. An aliquot (150 $\mu \mathrm{l})$ of total lipid extract (CM-FAMEs) was saponified and quantified as described previously for FAMEs. The remaining lipid extract $(300 \mu \mathrm{l})$ was separated into NLFA, glycolipid fatty acids (GLFA) and PLFA classes by silica gel chromatography (Drijber et al., 2000). Chloroform used to elute NLFA was freshly distilled.
Lipids were saponified and quantified as described above for FAMEs.

Fatty acids were designated as the total number of $\mathrm{C}$ atoms followed by a colon, the number of double bonds followed by the position of the double bond from the carboxyl end of the molecule and its cis or trans configuration (IUPAC-IUB, 1978). The prefixes a and i indicate antieso and iso branching, respectively; cy indicates cyclopropane fatty acids, br indicates an unknown branch position and $10 \mathrm{Me}$ indicates a methyl branch on the 10th $\mathrm{C}$ atom from the carboxyl end of the molecule. The C16:1cis11 FAME biomarker was selected to represent AM fungi (Olsson and Johansen, 2000).

\subsection{Statistical analysis}

Statistical analysis was performed with SAS Proc Mixed (SAS Institute, 1999) with sampling date and treatment (roller milled, nonroller milled) as fixed effects. Soil samples were collected from two locations on three sampling dates and divided into two treatments (roller milled, and nonroller milled). Variables analyzed included EL-FAMEs, CM-FAMEs and three lipid fractions (NLFA, GLFA and PLFA). Pearson correlations were also performed using SAS. Significance level for all comparisons was set a priori at $P<0.05$, and exceptions are stated.

\section{Results}

The concentration of the biomarker C16:1cis 11 , averaged over roller-milled and nonroller-milled treatments, was 1.5 fold greater for all dates in EL-FAMEs compared to CM-FAMEs, and increased over time in the ELFAMEs, CM-FAMEs and marginally $(P<0.07)$ in the GLFA fraction (Table 1). The concentration of C16:1 cis 11 in PLFAs was similar over time, and while NLFA

Table 1

Concentration (nmol g ${ }^{-1}$ soil) of $\mathrm{C} 16: 1$ cis 11 biomarker during reproductive growth and with roller milling

\begin{tabular}{|c|c|c|c|c|c|c|c|}
\hline Factor & EL-FAME & CM-FAME & NLFA & GLFA & PLFA & $\begin{array}{l}\text { NLFA/ } \\
\text { PLFA }\end{array}$ & $\mathrm{NLFA} / \mathrm{N}+\mathrm{G}+\mathrm{PLFA}$ \\
\hline \multicolumn{8}{|l|}{ Time } \\
\hline 4 Aug & $7.19 b$ & $4.35 b$ & 1.62 & $1.46 \mathrm{~b}^{\mathrm{a}}$ & 1.11 & 1.41 & 0.38 \\
\hline 23 Aug & $7.51 \mathrm{~b}$ & $4.02 \mathrm{~b}$ & 1.63 & $1.66 \mathrm{~b}$ & 1.26 & 1.26 & 0.33 \\
\hline 13 Sep & $10.57 \mathrm{a}$ & $7.27 \mathrm{a}$ & 2.10 & $3.52 \mathrm{a}$ & 1.23 & 1.74 & 0.34 \\
\hline $\mathrm{SE}$ & 0.37 & 0.47 & 0.41 & 0.54 & 0.04 & 0.35 & 0.08 \\
\hline \multicolumn{8}{|l|}{ Roller mill } \\
\hline No & $5.12 \mathrm{~B}$ & $3.50 \mathrm{~B}$ & $1.18 \mathrm{~B}$ & $0.90 \mathrm{~B}$ & 1.15 & $1.01 \mathrm{~B}^{\mathrm{a}}$ & 0.35 \\
\hline Yes & $11.72 \mathrm{~A}$ & $6.93 \mathrm{~A}$ & $2.39 \mathrm{~A}$ & $3.53 \mathrm{~A}$ & 1.25 & $1.93 \mathrm{~A}$ & 0.35 \\
\hline $\mathrm{SE}$ & 0.30 & 0.39 & 0.34 & 0.44 & 0.03 & 0.29 & 0.07 \\
\hline
\end{tabular}

EL-FAME = ester-linked fatty acid by mild alkaline hydrolysis; CM-FAME = ester-linked fatty acid by chloroform-methanol extraction; NLFA = neutral lipid fraction by chloroform-methanol extraction; GLFA = glycolipid fraction by chloroform-methanol extraction, PLFA = phospholipid fraction by chloroform-methanol extraction; $\mathrm{N}+\mathrm{G}+\mathrm{PLFA}=$ is the combined concentration of the NLFA, GLFA and PLFA fractions. Lower case letters stand for differences over time $(P=0.05$ unless stated otherwise) and capital letters represent differences between roller milled treatments.

${ }^{\text {a }}$ Significant at $P=0.07$ for GLFA over time, and for the ratio NLFA/PLFA by roller milling treatment. $N=12$. 


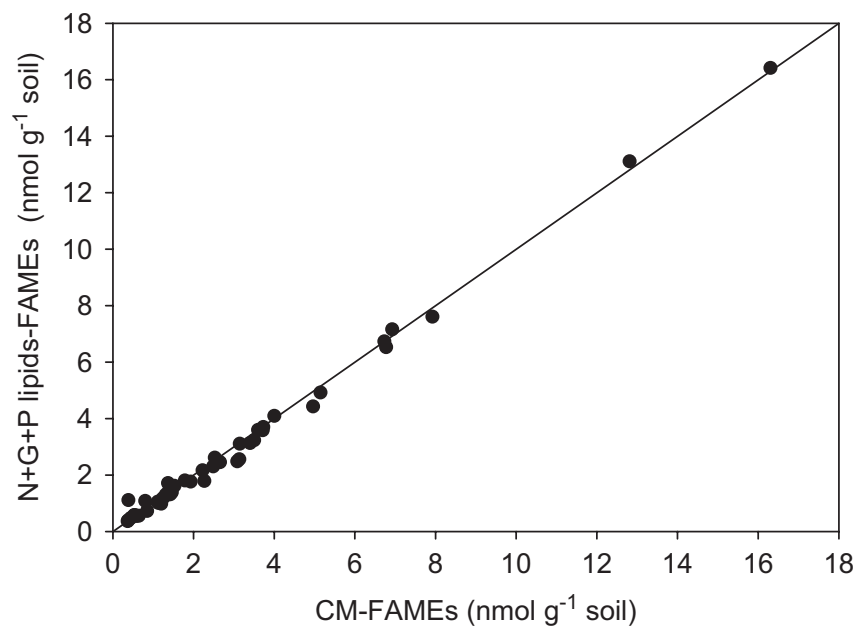

Fig. 1. Recovery of fatty acids from silica gel chromatography. Correlation between the sum of neutral $(\mathrm{N})$, glyco $(\mathrm{G})$ and phospholipids (P) fatty acid methyl esters (FAMEs) and chloroform methanol (CM) FAMEs. $N=12$.

C16:1 cis11 was higher in September this difference was not significant (Table 1). In addition, the ratio of NLFAs to PLFAs was similar over time. The relative concentration of NLFA over the combined concentration of NLFA, GLFA and PLFA C16:1cis11 was the same for all three sampling dates (Table 1). The relative concentration of GLFA C16:1 cis 11 was $45 \%$ of the combined concentration of the NLFA, GLFA and PLFA C16:1 cis11 lipid fractions, and did not change over time. Because PLFA C16:1cis11 did not increase over time, the relative concentration of PLFA C16:1 cis 11 decreased by $44 \%$ in September compared to the two sampling dates in August. The percent recovery of the NLFAs, GLFAs and PLFAs fractions was high $\left(y_{0}=-0.06, a=1, R^{2}=0.99, P<0.001\right)$ (Fig. 1).

Roller milling increased the concentration of C16:1cis 11 in the EL-FAMEs by $129 \%$ and CM-FAMEs by $98 \%$ (Table 1). This increase was due to the combined NLFA and GLFA C16:1cis 11 , which increased by $185 \%$ with roller milling. When considering only the NLFA C16:1 cis 11 biomarker, the increase was only $103 \%$.

\subsection{Efficiency of extraction of FAMEs from roller-milled soil}

Roller milling increased efficiency of extraction of specific EL- and CM-FAMEs (Fig. 2). The fatty acids $i \mathrm{C} 15: 0, \quad a \mathrm{C} 15: 0, \quad \mathrm{C} 15: 0, \quad i \mathrm{C} 16: 0, \mathrm{C} 16: 1$ cis $7, \quad \mathrm{C} 16: 1$ cis 9 , $10 \mathrm{MeC} 17: 0, \quad i \mathrm{C} 17: 0, \quad a \mathrm{C} 17: 0, \quad \mathrm{C} 17: 1$ cis $9, \quad \operatorname{cyC} 17: 0(9,10)$, i10MeC18:0, 10MeC18:0, $\mathrm{C} 18: 0, \quad c y \mathrm{C} 19: 0(11,12)$ and C20:4 $(5,8,11,14)$ closely followed a 1 to 1 line indicating similar efficiency of extraction before and after roller milling. The linear regression was significant for both ELFAMEs $\left(y_{0}=0.51, a=1, R^{2}=0.96\right)$ and CM-FAMEs $\left(y_{0}=0.28, a=1, R^{2}=0.94\right)$. The following fatty acids did not follow this distribution: C16:0, C16:1cis11, C18:1cis9, $\mathrm{C} 18: 1$ cis 11 and $\mathrm{C} 18: 2$ cis 9,12 . The linear regression was not
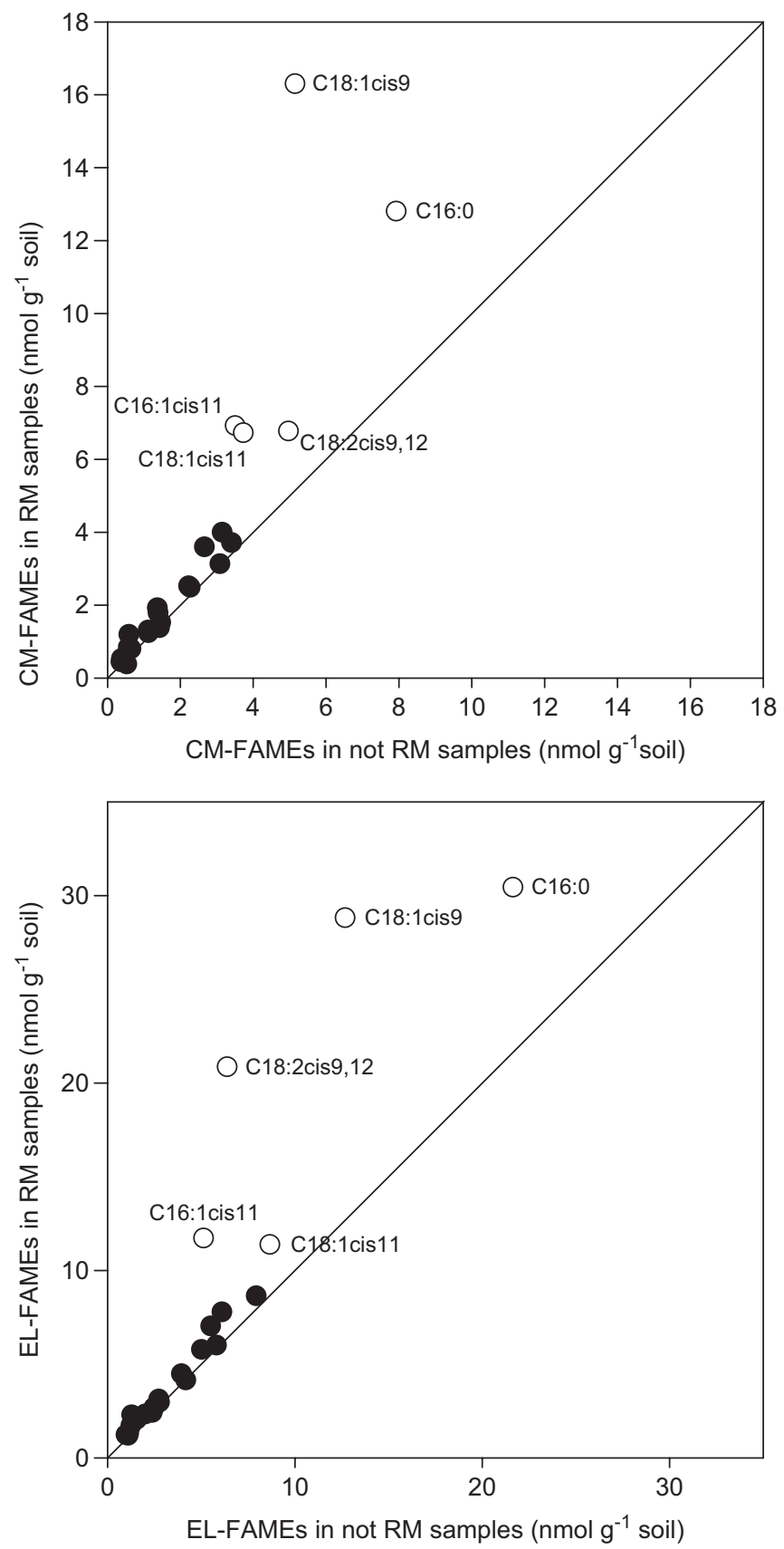

Fig. 2. Correlation between nonroller-milled (not RM) and roller-milled (RM) soil samples for chloroform-methanol extracted fatty acid methyl esters (CM-FAMEs) or ester-linked FAMEs (EL-FAMEs). $N=6$.

significant for these fatty acids: EL-FAMEs $\left(y_{0}=9.8\right.$, $\left.a=1, R^{2}=0.62\right)$ and the CM-FAMEs $\left(y_{0}=4.9, a=1\right.$, $\left.R^{2}=0.30\right)$.

\subsection{Distribution of C16:1 cis11 among lipid fractions}

The C16:1cis 11 fatty acid present in EL-FAMEs covaried with the concentration in the CM-FAMEs, and showed that both methods of lipid analysis extracted fatty acids from similar pools (Table 2), even if the concentrations differed (Table 1). The correlation was also high 
Table 2

Correlation of C16:1cis11 FAME biomarker among lipid pools

\begin{tabular}{|c|c|c|c|c|c|c|}
\hline & NLFA & GLFA & PLFA & GLFA + NLFA & CM-FAME & EL-FAME \\
\hline NLFA & 1 & & & & & \\
\hline GLFA & 0.24 & 1 & & & & \\
\hline PLFA & 0.36 & 0.46 & 1 & & & \\
\hline GLFA + NLFA & $0.62 *$ & $0.91 * *$ & $0.52 \Phi$ & 1 & & \\
\hline CM-FAME & $0.59^{*}$ & $0.88^{* *}$ & $0.50 \Phi$ & $0.96^{* *}$ & 1 & \\
\hline EL-FAME & $0.61 *$ & $0.89 * *$ & $0.49 \Phi$ & $0.98 * *$ & $0.92 * *$ & 1 \\
\hline
\end{tabular}

EL-FAME = ester-linked fatty acid by mild alkaline hydrolysis; CM-FAME = ester-linked fatty acid by chloroform-methanol extraction; NLFA = neutral lipid fraction by chloroform-methanol extraction; GLFA = glycolipid fraction by chloroform-methanol extraction, PLFA = phospholipid fraction by chloroform-methanol extraction; NLFA + GLFA = combined concentration of these two fractions. $N=12$.

$\Phi, *{ }^{* *}$, Correlation between measured attributes is significant at the $0.1,0.05$ and 0.01 levels, respectively.

between GLFA and NLFA C16:1cis11, separately or combined, and the EL- and CM-FAMEs. The concentration of C16:1cis11 in the most polar lipid fraction (PLFA) covaried with CM-FAMEs and EL-FAMEs, however this correlation was marginally $(P<0.1)$ significant. The correlation among the NLFAs, GLFAs and PLFAs was not significant.

\subsection{Dynamics of C16:1 cis11 in roller-milled vs. nonroller- milled soil}

The mean concentration of CM-FAME C16:1cis11 in nonroller-milled samples increased $157 \%$ from August to September and the combined concentration of NLFA and GLFA C16:1 cis 11 increased 204\% (Fig. 3). The increase in EL-FAME C16:1cis11 from August to September was $55 \%$. In roller-milled samples, the increase from August to September was $42 \%$ for CM-FAME, $39 \%$ for EL-FAME and $45 \%$ for the combined concentration of NLFA and GLFA C16:1cis11 (Fig. 3). The concentration of PLFA C16:1cis11 showed no increase over time or due to roller milling.

\section{Discussion}

\subsection{Roller milling enhances extraction of fungal biomarkers}

Roller milling the soil increased the recovery of EL- and CM-FAMEs common to saprophytic fungi (C16:0, C18:1cis9, C18:2cis9,12) and AM fungi (C16:0, C16:1cis11, C18:1cis11) but not those specific to bacteria or the faunal marker C20:4. This increase was attributed to increased extraction efficiency of resistant fungal structures, such as rhizomorphs and spores, disrupted by the milling action. In contrast, Madan et al. (2002) found that crushing the spores prior to lipid extraction caused a small (but nonsignificant) decreases in the yield of fatty acids detected in several AM fungi. Disruption of soil aggregates by roller milling did not enhance recovery of bacterial FAMEs indicating adequate penetration of solvent by both extraction methods into dry soil aggregates of this mediumtextured soil.
Roller milling significantly increased the amount of C16:1 cis11 in the NLFA and GLFA fractions. Although PLFA C16:1cis11 also increased, it was not significant. Olsson and Johansen (2000) extracted lipids from 3-monthold AM mycelium and found that ball milling enhanced the yield of NLFA $16: 1$ cis 11 by $733 \%$ and the NLFA/PLFA ratio was increased by $249 \%$. The estimated biomass of spores vs. mycelium was high and would account for these values. In our study, the yield of NLFA increased by $102 \%$ and the NLFA/PLFA ratio was $91 \%$ higher in roller milled than in nonroller-milled samples. This would suggest a greater mycelial (or nonspore) biomass in the soil chambers. This is supported by the NLFA C16:1 cis 11 accounting for the same proportion of the total CM-FAMEs in roller milled and nonroller-milled soils. This ratio would be expected to increase significantly with a high spore population. Thus, increased concentration of C16:1cis11 in roller-milled soil reflects increased overall extraction efficiency from all AM fungal structures within the chambers, not enhanced extraction from selected resistant structures such as spores. Furthermore, Olsson and Johansen (2000) also observed that most PLFAs are easily removed from mature spores using the Bligh and Dyer procedure, while ball milling increased the yield of PLFA C16:1cis11 extracted from mycelium.

Roller milling increased the proportion of C16:1 cis 11 recovered in GLFA (292\%) compared to NLFA (102\%). This suggests more than one source for these complex lipids, or that glycolipids account for a greater proportion of the fungal biomass disrupted by roller milling than neutral lipids. Jabaji-Hare et al. (1984) studied the total lipid content of Glomus vesicles, and found that glycolipids represented $44.5 \%$ of the total lipid. Greater disruption of plant roots by roller milling may have led to increased recovery of AM lipids from intraradical fungal structures. Further studies are required to identify the sources of these complex lipids in fungal structures.

\subsection{Suitability of lipid fractions for measuring AM biomass in field soil}

Olsson and Johansen (2000) showed that the amount of PLFA 16:1cis11 per unit of biomass remained constant as 
a

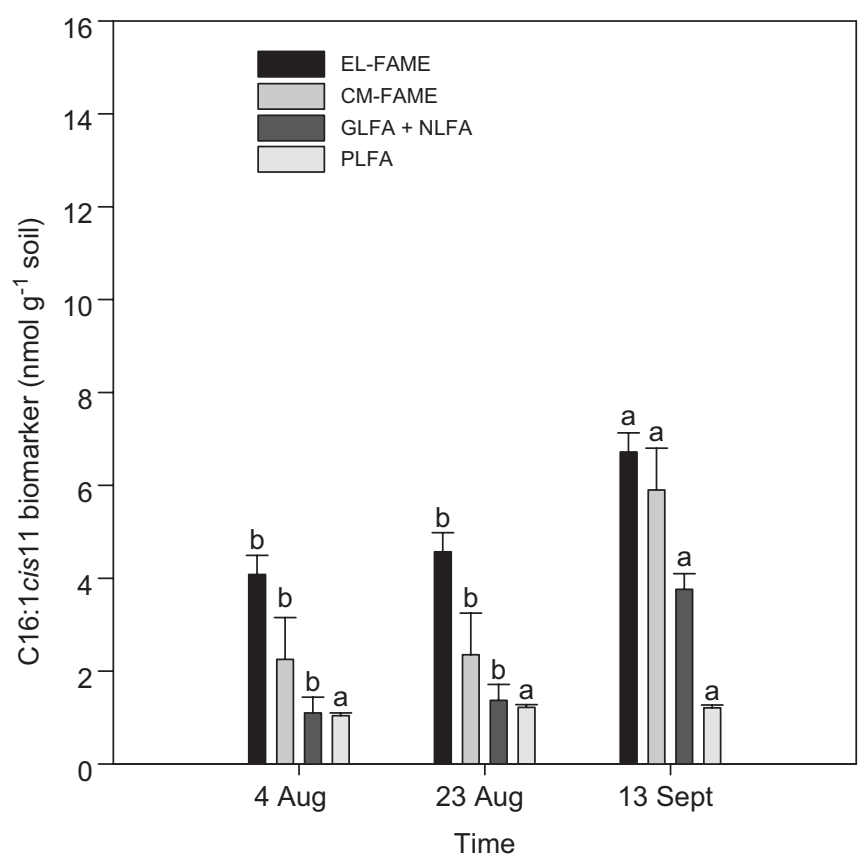

b

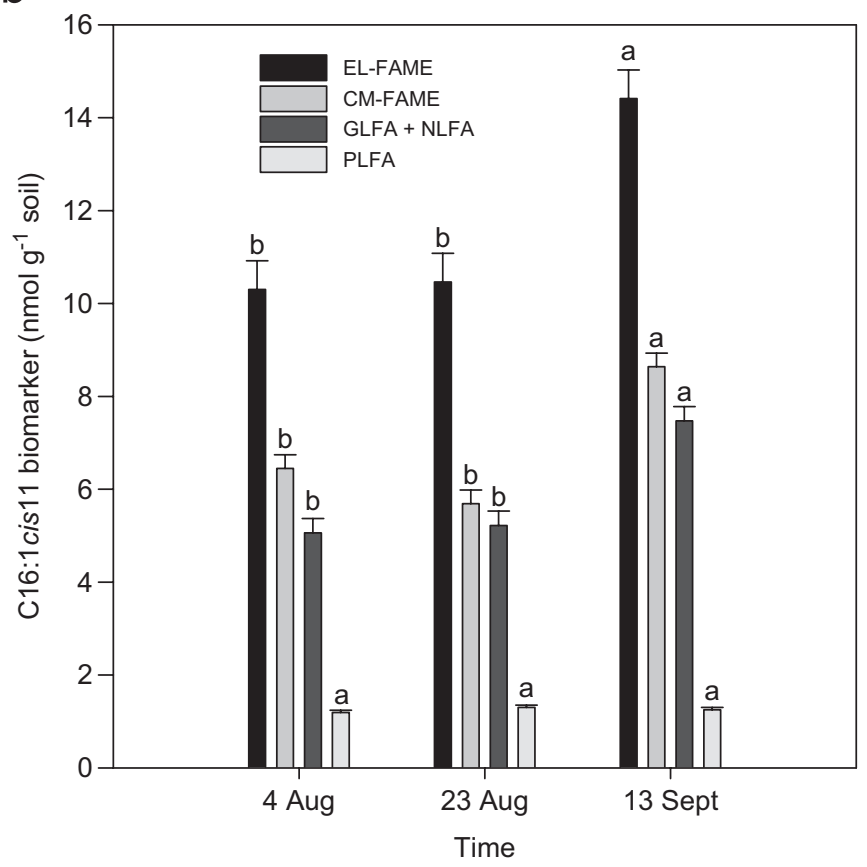

Fig. 3. Dynamics of the C16:1 cis 11 biomarker over time in (a) nonrollermilled soil samples, and (b) in roller-milled soil samples. EL-FAMEs = ester-linked fatty acids by mild alkaline hydrolysis; CM-FAMEs = esterlinked fatty acids by chloroform-methanol extraction; NLFA = neutral lipid fraction by chloroform-methanol extraction; GLFA = glycolipid fraction by chloroform-methanol extraction, PLFA = phospholipid fraction by chloroform-methanol extraction. Letters stand for significant differences $(P=0.05)$ among sampling dates. $N=2$.

the mycelium aged and was a good indicator of AM biomass. Although PLFA C16:1cis11 has been used successfully to quantify the dynamics of AM biomass in sand-culture systems, its utility has been questioned for field soils (Olsson, 1999). We found under field conditions, no significant changes in the PLFA C16:1 cis11 concentration in soils thus our study supports this premise. Olsson and Wilhelmsson (2000) buried mesh bags and tubes containing initially mycelium-free sand in sand dunes near the roots of Ammophila arenaria L., and removed them after 35 and 68 days. They observed mean concentrations of C16:1 cis11 PLFA of $46 \mathrm{pmol} \mathrm{g}^{-1}$ sand after 35 days and $41 \mathrm{pmol} \mathrm{g}^{-1}$ sand after 68 days. If we assume similar net accumulations of PLFA in the chambers over time, background concentrations of C16:1cis11 PLFA were several orders of magnitude higher making detection of new AM growth using PLFA impossible. This limitation led to the use of NLFA C16:1 cis11 as a measure of AM biomass in field soils (Olsson, 1999).

Lipid synthesis occurs in intraradical fungal structures using plant $\mathrm{C}$ that is then translocated to the extraradical mycelium (Pfeffer et al., 1999). Neutral lipids accumulate as mycelia age and are evidence for successful root colonization, and subsequent sporulation (Olsson and Johansen, 2000). Olsson and Wilhelmsson (2000) observed that NLFA C16:1cis11 was a sensitive tool for the detection of AM fungi mycelium in their field study. Although mean concentrations of NLFA C16:1 cis11 increased during the 9 weeks of our experiment, it was not significant. Our results contradict previous reports under field conditions, possibly due a high background concentration of NLFA. We did observe a significant doubling in GLFA C16:1 cis11 later in the corn season; however, there is minimal mention of this lipid fraction in the literature. We suggest that NLFA and GLFA C16:1 cis 11 have a complementary dynamic under field conditions and during the reproductive stages of corn, but future studies are required to understand its significance in terms of fungal growth and development.

\subsection{Dynamics of AM biomarkers in chamber soil during the reproductive stages of corn}

\subsubsection{GLFA C16:1cis11}

The increase in GLFA C16:1cis11 observed in our research may be related to the synthesis of specific membranes and structures as part of the pre-sporulation process. Nemec (1981) studied the histochemical characteristics of Glomus etunicatus. He suggested that the arbuscule wall is composed primarily by glycolipids, and its osmophilic and acidic properties would facilitate bidirectional flow of nutrients.

In our study, the relative concentration of GLFA C16:1 cis 11 was $45 \%$ and was higher than the proportion of NLFA and PLFA. Jabaji-Hare et al. (1984) studied the total lipid content of Glomus vesicles, and found that glycolipids represented $45 \%$ of the total lipid. They also found that the most abundant fatty acid was 16:1 in the neutral and glycolipid fractions. In our study, glycolipids composed $28 \%$ of the total fatty acids extracted from our nonroller-milled samples and 50\% from the roller-milled 
samples. The percentage we report for soil extracts is similar to previous studies for pure culture extracts.

The increase in GLFA C16:1 cis11 later in the corn season was likely due to a change in lipid synthesis pathways, with a clear dominance of glycolipids (observed in the roller-milled samples) over the other fractions. One explanation may be that as the crop matures a reduction in C supply to AM fungi between R5 and R6 stage of corn may trigger the production of glycolipids in spore-related structures formed by symbiotic fungi. Bago et al. (1998) observed in Glomus intraradices that arbuscules develop along intraradical, intercellular hyphae or intracellular coils, while branched absorbing structures (BAS) are formed on extraradical mycelia, possibly associated with spore formation. Arbuscules and BAS share several cytological characteristics: both contain numerous nuclei, mitochondria, glycogen deposits, lipid globules, abundant polyvesicular bodies and electrodense granules inside small vacuoles (Bonfante-Fasolo, 1984; Bago et al., 1998). In plants, steryl glucosides and their acylated derivatives (GLFA) are located in microsomal and mitochondria membranes (Harwood, 1977). Gavito et al. (2001) concluded that the shortage of $\mathrm{C}$ belowground during flowering of Pea (Pisum sativum cv. Solara) was associated with an increase in root senescence and changes in AM fungal phenology. The fungi switched from an active colonization phase to a reproductive phase, when storage structures such as vesicles and spores (and possibly BAS) are typically formed. In our study, this switch may explain the increase in GLFA after R5.

\subsubsection{The combined concentration of NLFA and GLFA C16:1 cis11}

Glycolipids are easily extracted from fungal cells with organic solvents, but they exhibit many of the solubility properties of neutral lipids and are weakly absorbed by silicic acid. For these reasons, they were included in the neutral lipid fraction in much of the earlier work and did not receive detailed attention (Brennan et al., 1974). Today, it is difficult to find references to fungal glycolipids. Variations in methodology (i.e. column selection, solvent preparation, solvent elution volumes, etc.) for the separation of the neutral and glycolipid fractions makes it difficult to make comparisons among studies. A standardized protocol is needed before comparison of lipid fractions among studies is possible.

Given the methodological inconsistencies stated above, the increase in the concentration of NLFA C16:1 cis11 over time, the lack of knowledge of GLFA C16:1 cis11, and the significance of the correlation among NLFA and GLFA with EL- and CM-FAME C16:1cis11, we combined the concentration of the NLFA and GLFA C16:1 cis11 fractions to explain the dynamics of $\mathrm{C}$ partition during the reproductive stages of corn. There was an increase over time of the storage/structural lipids (represented by the increase in the combined concentration of NLFA and GLFA C16:1cis11) over time, which confirms an allocation of $\mathrm{C}$ from the plant to the symbiont. The proportional increase over time of the combined concentration of NLFA and GLFA biomarker was greatest in the nonroller-milled samples. This would indicate that the increase in storage and structural lipids over time was not mainly in resistant structures, but in structures easily extracted with organic solvents.

\subsection{EL-FAMEs as a simple measure of AM colonization of soil}

We propose the simple EL-FAME extraction procedure for routine measurement of AM biomass in soils based on the following: (1) the concentration of the AM fungal marker, C16:1 cis11, was greater in EL-FAMEs, but highly correlated to CM-FAMEs $(r=0.92, P=0.01)$ in both roller-milled and nonroller-milled soils suggesting extraction from similar structures within AM biomass. This higher concentration of C16:1 cis 11 in EL-FAMEs probably reflects easier methanolysis and solubilization of fatty acids compared to removal of intact complex lipids from fungal cells. (2) The amount of C16:1cis11 extracted by both methods is largely driven by GLFA and to a lesser degree by NLFA. (3) In soils without prior grinding, both methods would be relatively inefficient at extracting spores and thus reflect largely the extramatical AM hyphal network important for nutrient acquisition by the plant.

\section{Conclusion}

Under field conditions, fungi have lipid-containing resistant structures that become more extractable after roller milling the soil. These more resistant structures are possibly spores or rhizomorphs, or intramatrical AM structures within roots. EL-FAME and CM-FAME C16:1 cis11 biomarkers reflected an increase in NLFA and GLFA, and were related to storage lipids and resistant structures synthesized de novo during the reproductive stages of corn. NLFA C16:1 cis11 alone was not adequate to measure the dynamics of indigenous AM fungi in these soils. We suggest using both NLFA and GLFA C16:1 cis 11 to study $\mathrm{C}$ allocation and $\mathrm{AM}$ fungal dynamics in agroecosystems. The simple EL-FAME extraction procedure is recommended for routine measurement of AM biomass in soils.

\section{References}

Arnold, S.L., Schepers, J.S., 2004. A simple roller-miller grinding procedure for plant and soil samples. Communication in Soil Science and Plant Analysis 35, 537-545.

Bago, B., Azcón-Aguilar, C., Goulet, A., Piché, Y., 1998. Branched absorbing structures (BAS): a feature of the extraradical mycelium of symbiotic arbuscular mycorrhizal fungi. New Phytologist 139, 375-388.

Bonfante-Fasolo, P., 1984. Anatomy and morphology of VA mycorrhizae. In: Powell, C.L., Bagayaraj, D.J. (Eds.), VA Mycorrhiza. CRC Press, Boca Raton, FL, USA pp. 5-33. 
Brennan, P.J., Friffin, P.F.S., Losel, D.M., Tyrrell, D., 1974. The Lipids of Fungi. Pergamon Press Ltd., Oxford, 89pp.

Drijber, R.A., Doran, J.W., Parkhurst, A.M., Lyon, D.J., 2000. Changes in soil microbial community structure with tillage under long-term wheat-fallow management. Soil Biology \& Biochemistry 32, 1419-1430

Gaspar, M.L., Pollero, R.J., Cabello, M.N., 1994. Triacylglycerol consumption during spore germination of vesicular-arbuscular mycorrhizal fungi. Journal of the American Oil Chemists' Society 71, 449-452.

Gaspar, M.L., Pollero, R.J., Cabello, M.N., 1997. Partial purification and characterization of a lipolytic enzyme from spores of the arbuscular mycorrhizal fungus Glomus versiforme. Mycologia 89, 610-614.

Gavito, M.E., Curtis, P.S., Jakobsen, I., 2001. Neither mycorrhizal inoculation nor atmospheric $\mathrm{CO}_{2}$ concentration has strong effects on pea root production and root loss. New Phytologist 149, 283-290.

Graham, J.H., Hodge, N.C., Morton, J.B., 1995. Fatty acid methyl ester profiles for characterization of Glomalean fungi and their endomycorrhizae. Applied and Environmental Microbiology 61, 58-64.

Grigera, M.S., Drijber, R.A., Wienhold, B.J., 2007. Increased abundance of arbuscular mycorrhizal fungi in soil coincides with the reproductive stages of maize. Soil Biology \& Biochemistry, in press, doi:10.1016/ j.soilbio.2006.11.025.

Harwood, J.L., 1977. Glycolipids of fungi and plants. Biochemical Society Transactions 5, 1677-1682.

IUPAC-IUB, 1978. The nomenclature of lipids. Journal of Lipid Research 19, 114-128.

Jabaji-Hare, S., Perumalla, C.J., Kendrick, W.B., 1984. Auto-fluorescence of vesicles, arbuscules, and intercellular hyphae of a vesiculararbuscular fungus in leek (Allium porrum) roots. Canadian Journal of Botany 62, 2665-2669.

Johnson, C.K., Wienhold, B.J., Doran, J.W., Drijber, R.A., Wright, S.F., 2004. Linking microbial-scale finding to farm-scale outcomes in a dryland cropping system. Precision Agriculture 5, 311-328.
Madan, R., Parkhurst, C., Hawke, B., Smith, S., 2002. Use of fatty acids for identification of AM fungi and estimation of the biomass of AM spores in soil. Soil Biology \& Biochemistry 34, 125-128.

Nemec, S., 1981. Histochemical characteristics of Glomus etunicatus infection of Citrus limon fibrous roots. Canadian Journal of Botany 59, 609-617.

Olsson, P.A., 1999. Mini review. Signature fatty acids provide tools for determination of the distribution and interactions of mycorrhizal fungi in soil. FEMS Microbiology Ecology 29, 303-310.

Olsson, P.A., Johansen, A., 2000. Lipid and fatty acid composition of hyphae and spores of arbuscular mycorrhizal fungi at different growth stages. Mycological Research 104, 429-434.

Olsson, P.A., Wilhelmsson, P., 2000. The growth of external AM fungal mycelium in sand dunes and in experimental systems. Plant and Soil 226, 161-169.

Olsson, P.A., Bååth, E., Jakobsen, I., 1997. Phosphorus effects on the mycelium and storage structures of an arbuscular mycorrhizal fungus as studied in the soil and roots by analysis of fatty acid signatures. Applied and Environmental Microbiology 63, 3531-3538.

Pfeffer, P.E., Douds, D.D., Bécard, G., Shachar-Hill, Y., 1999. Carbon uptake and the metabolism and transport of lipids in and arbuscular mycorrhiza. Plant Physiology 120, 587-598.

Ritchie, S.W., Hanaway, J.J., Benson, G.O., 1997. How a Corn Plants Develops. Special Publication 48. Iowa State University Cooperation Extended Services, Ames.

SAS Institute Inc, 1999. SAS/STATs User's Guide, Version 8. SAS Institute Inc., Cary, NC.

Smith, S.E., Read, D.J., 1997. Mycorrhizal Symbiosis. Academic Press, London, 587pp.

van Aarle, I.M., Olsson, P.A., 2003. Fungal lipid accumulation and development of mycelial structures by two arbuscular mycorrhizal fungi. Applied and Environmental Microbiology 69, 6762-6767.

White, D.C., Davis, W.M., Nickels, J.S., King, J.D., Bobbie, R.J., 1979. Determination of the sedimentary microbial biomass by extractable lipid phosphate. Oecologia 40, 51-62. 